\title{
A novel rotor design for a hybrid excited synchronous machine
}

\author{
Piotr PAPlicki \\ West Pomeranian University of Technology Szczecin \\ Department of Power Systems and Electrical Drives \\ Sikorskiego 37, 70-313 Szczecin, Poland \\ e-mail:paplicki@zut.edu.pl
}

(Received: 20.11.2015, revised: 23.02.2016)

\begin{abstract}
The paper presents three novel rotor design concepts for a three-phase electric controlled permanent magnet synchronous machine (ECPMS-machine) with hybrid excitation. The influence of magnets and flux-barriers arrangement on the magnetic field distribution and field-weakening characteristics of the machine is examined, based on a three-dimensional finite element analysis (3D-FEA). Moreover, a prototype rotor design based on a new rotor concept with a good field-weakening capability is presented in detail. Finally, the experimental results of no-load back electromotive force (back-EMF) waveforms and field-weakening characteristics versus a control coil current of the machine are reported.

Key words: experimental result, field-weakening, finite element analysis, hybrid excitation, PM machine, rotor design
\end{abstract}

\section{Introduction}

At present, we are witnessing a continuing development of electrical machines used in variable-speed applications, such as wind turbines and automobiles. Numerous applications, such as the electric vehicle (EV) drive, require constant-voltage operation over a broad range of speeds. Depending on the operating conditions, the traction characteristics imply the use in two operation regions, namely: constant torque and constant power. An extended constant power range capability is crucial in reducing the power supply volt-ampere rating. Therefore, optimal applications for an EV drive for a hybrid electric vehicle (HEV), or a battery electric vehicle (BEV), should offer a field weakening potential of at least 1:4. It can be obtained, for instance, by connecting two kinds of excitation. Using machines with electromagnetic excitation, the required operating mode is achieved by an appropriate reduction of the field excitation current when the speed increases. In permanent magnet (PM) excited machines, constant excitation flux can only be controlled from the stator side by injecting the $d$-axis current. 
It leads to an increase in winding losses and decreases efficiency of the entire drive system. In a hybrid excited PM machine (HEPM-machine), the extended constant power range is achieved by combining PM and electrical excitation. Thanks to an additional DC field excitation winding, a direct adjustment of the magnetic flux of the HEPM-machine is implemented. Various machine topologies with hybrid excitation have been described in literature, e.g. $[1-5,13]$.

The purpose of this paper is to explore three new rotor magnetic structure concepts for an Electric Controlled Permanent Magnet Synchronous machine (ECPMS-machine) with field weakening capability, which has been developed and widely tested in [6]. Furthermore, preliminary PM arrangement optimization methods of extending the field-weakening capability and reducing the cogging torque of the machine have been proposed in [7].

\section{Flux distribution in the ECPMS-machine}

The main features and properties of the ECPMS-machine shown in Fig. 1 derive from the use of a powder composite material mixture with an epoxy resin addition technology. The technology has been used to form a solid stator core and a rotor core with iron poles of the machine. As reported in [6], the implementation of this version of the machine allows to control the field excitation within the range of $\pm 30 \%$ only. As a result, the speed of the machine is nearly doubled.

In order to explore the magnetic structure and clearly understand the role of the additional field-excitation in the magnetic field distribution of the ECPMS-machine, a cross section of the machine, including a virtual view of the magnetic flux paths, have been presented in Fig. 1. It is important to note that some of the flux paths have only appeared within a fieldweakening region.

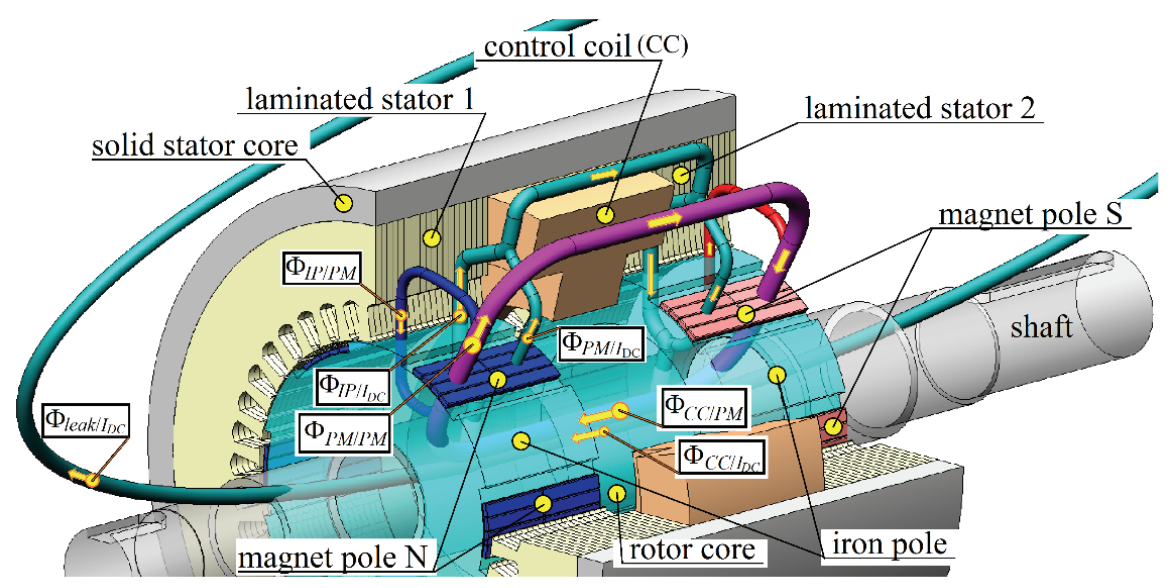

Fig. 1. Cross-section of the ECPMS-machine and virtual view of magnetic flux paths by weakening condition at $I_{D C}>0$ 
By neglecting the saturation effect and the magnet flux leakage of the machine, it can be assumed that a flux component generated by PMs $\left(\Phi_{P M / P M}\right)$ crosses an air-gap over magnet pole $\mathrm{N}$ section in the radial direction and flows through a laminated stator 1 . The main part of the flux $\Phi_{P M / P M}$ is passed through a solid stator core in the axial direction and subsequently returned through an air-gap over the magnet pole $\mathrm{S}$ section to the magnet pole $\mathrm{N}$ section via a rotor core in the form of a flux $\Phi_{C C / P M}$. The remaining part of the flux $\Phi_{P M / P M}$ passes through the stator core 1 and is returned to the magnet pole $\mathrm{N}$ section through the air-gap over the iron pole section in the form of a flux $\Phi_{I P / P M}$.

When a current $I_{D C}$ of a control coil (CC) is injected, additional DC field excitation is achieved. In this case, the flux $\Phi_{C C}$ passing through the control coil in the axial direction can be expressed as a combination of the flux $\Phi_{C C / P M}$ generated by the PMs and the flux $\Phi_{C C / I_{D C}}$ generated by the current $I_{D C}$. The flux $\Phi_{C C}$ is passed through a magnetic shaft and the rotor core in the axial direction and a significant portion of it returns to the air-gap of the machine, where it is divided into two components: flux $\Phi_{P M / I_{D C}}$ crosses the air-gap over the magnet pole section and $\Phi_{I P / I_{D C}}$ crosses the air-gap over the iron pole section.

The remaining portion of the flux $\Phi_{C C}$ creates a flux leakage, comprised of both axial and radial components.

Neglecting armature effects and saturation, using the principle of flux superposition, the resulting air-gap fluxes, excited in the field-weakening region, can be decomposed into PM excitation and additional DC field excitation by the current $I_{D C}$. The linear model of the resulting air-gap flux over the magnet pole section $\Phi_{P M}$ and the resulting flux over the iron pole section $\Phi_{I P}$ can be expressed as:

$$
\begin{gathered}
\Phi_{P M}=\Phi_{P M / P M}+\Phi_{P M / I_{D C}}, \\
\Phi_{I P}=-\Phi_{I P / P M}+\Phi_{I P / I_{D C}} .
\end{gathered}
$$

It should be noted that, the design of a rotor magnetic circuit structure ECPMS-machine is crucial because of the field-weakening and flux leakage issues. The fixed additional DC field excitation, apart from the increase of the size of the machine also increases the leakage inductance of the control coil fixed on the stator. Hence, it is very important to determine the flux leakage of the machine particularly between no-load and under injected current of the control coil conditions. The linear model of the resultant control coil flux $\Phi_{C C}$ and the axial flux leakage $\Phi_{\text {leak } / I_{D C}}$ generated by the additional DC field excitation in the field-weakening region, can be defined as:

$$
\begin{gathered}
\Phi_{C C} / p=\Phi_{C C / P M}+\Phi_{C C / I_{D C}}, \\
\Phi_{\text {leak } / I_{D C}}=\Phi_{C C} / p-\Phi_{P M / I_{D C}}-\Phi_{I P / I_{D C}},
\end{gathered}
$$

where: $\Phi_{C C / P M}$ is the control coil flux component created by PMs, $\Phi_{C C / I_{D C}}$ is the control coil flux component created by the additional DC field excitation by the current $I_{D C}, p$ is the number of pair of poles. 
In order to show the principal change in the magnitude of fluxes from the additional DC field excitation, Fig. 2 presents the 2-D air-gap magnetic flux density distribution over a magnet and iron pole pitch. As illustrated in Fig. 2, it can be assumed that the polarity of the resulting flux over the iron pole section changes as a result of the addition field excitation by the current $I_{D C}>0$, in this case $I_{D C}=2.0 \mathrm{~A}$ (2500 Ampere-turns).

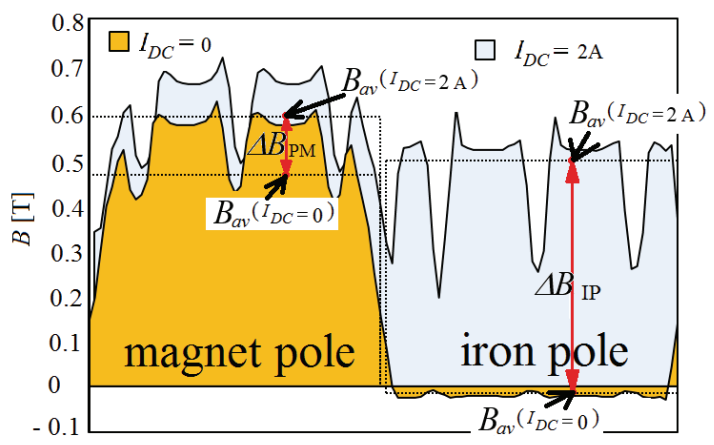

Fig. 2. Air-gap flux density distribution over magnet pole and iron pole pitch of the M1 model

The essence of increasing the flux linked with the stator phases is based on an equalization of fluxes passed through the magnet $\Phi_{P M}$ and the iron pole $\Phi_{I P}$ section. Therefore, rotor magnetic circuit structures for the ECPMS-machine should be developed, in which the additional DC field excitation strongly increases the iron pole flux $\Phi_{I P}$ only, simultaneously maintaining the magnet pole flux $\Phi_{P M}$. This objective can be achieved by developing effective magnetic flux diverters in the rotor magnetic circuit of the machine.

Fig. 3a shows the initial, previously presented, structure of the rotor ECPMS-machine with surface-mounted PM (M1), analyzed in detail in [12], as well as three new rotor design concepts (M2-M4) for the machine. It should be noted that, in all cases, the machine has the parallel hybrid excitation system.

In the M2 model, the magnet poles are formed by quadrant-cylinder PMs and they are placed alternately between the iron poles. Due to the relatively high reluctance of the large volume quadrant-cylinder magnet, a natural path for leading flux through the ferromagnetic iron poles is formed. As a result, a substantial portion of the flux $\Phi_{C C / I_{D C}}$ component created by the control coil current can be diverted into the iron pole section. Thus, it can be assumed that the magnetic flux passing through the iron pole $\Phi_{I P}$ can be effectively regulated by the additional DC field excitation.

In the M3 model, each magnet pole is formed by a single surface-mounted PM and two magnets locked in radially arranged holes. The holes also serve as radial flux barriers (RFB). A single embedded flux barrier (EFB) is located below the RFBs.

In the M4 model, the magnet pole is formed by two embedded PMs and two magnets are locked in the RFBs. Similarly to the M3 model, a single EFB is formed in each iron pole section. 


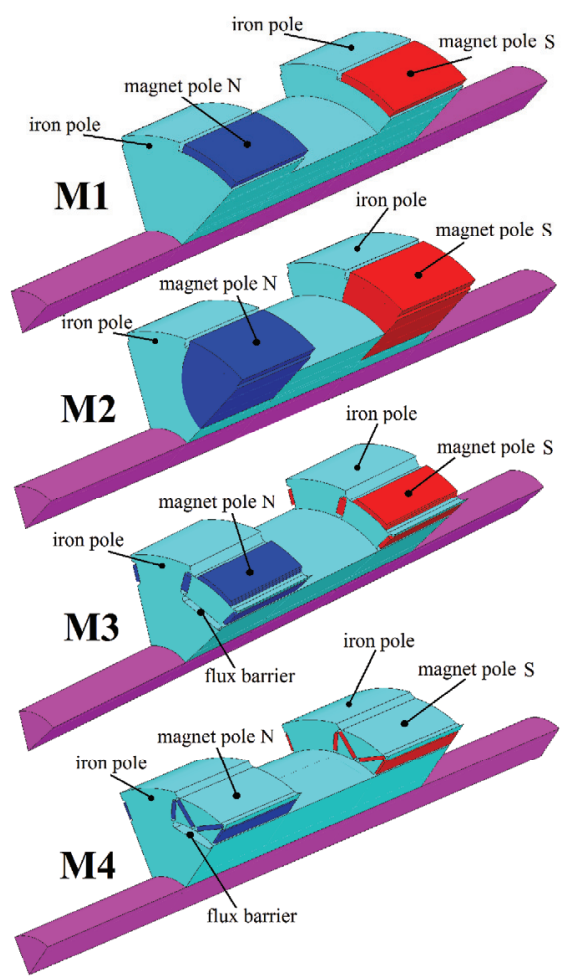

a)
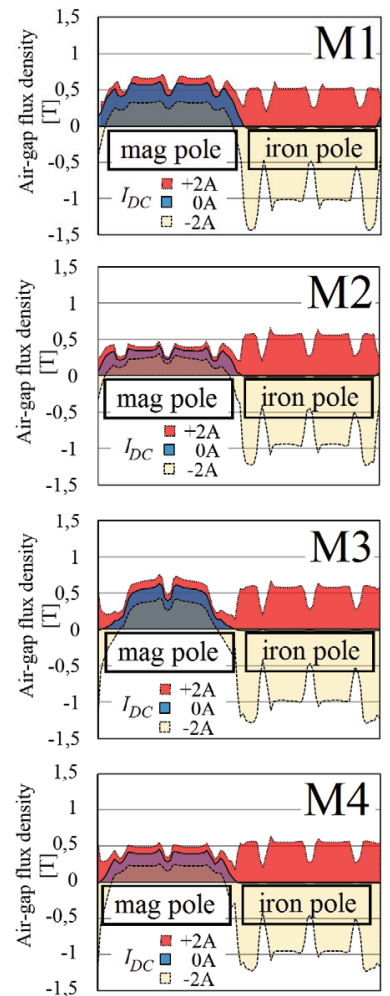

Fig. 3. Rotor design concepts for the ECPMS-machine (a); 2-D air-gap flux density distribution in the M1-M4 models at three field excitation levels (b), in comparison

\section{Influence of the arrangement of magnets and flux barriers on ECPMS-machine flux control}

In order to examine the influence of magnet type, shape, orientation, grouping and flux barrier arrangement for an ECPMS-machine on the field control capability, a 3-D FEA was carried out. The main goal of this investigation was to determine the field-weakening capability of the machine and to verify the equations that had been developed previously. This time, the nonlinear magnetization curve (B-H curve) was taken into account.

During the design and analysis of the saturation effect on the field control of the machine, it was assumed that an $\mathrm{NdFeB}$-type permanent magnet (N38SH-type) would be used in the M1, M3 and M4 models. In the M2 model, a ferrite magnet (F30) has been used in order to avoid the saturation effects caused by the considerable size of the quadrant-cylinder magnet.

Fig. 3b shows the 2-D air-gap flux density distribution in all models at three different field excitation levels: field-weakening at $I_{D C}=2.0 \mathrm{~A}$, a field without additional excitation at $I_{D C}=0$, and, additionally, field-strengthening at $I_{D C}=-2.0$ A. As seen in Fig. 3(b), the air-gap 
flux density waveforms and their changes are different for all models. Moreover, it can be observed that a particularly effective increase of the flux $\Phi_{I P / I_{D C}}$ crossing the air-gap over the iron pole is noticeable in the M2 and M4 models. In order to clearly determine the effect of flux changes of the machine, a PM pole growth flux ratio $\Delta \Phi_{P M}$ and an iron pole growth flux ratio $\Delta \Phi_{I P}$ were determined. In this case, the growth flux ratio means a ratio of fluxes passed through the magnet pole/iron pole at $I_{D C}=2.0$ A (field-weakening) to fluxes passed through the magnet pole/iron pole without the additional excitation (at $I_{D C}=0$ ). 3D-FEA results of the mean values of the air-gap flux density over the PM pole $\left(B_{P M}\right)$ and the iron pole $\left(B_{I P}\right)$ with fluxes $\Phi_{P M}$ and $\Phi_{I P}$ of the ECPMS-machine for all models were listed in Table 1.

Table 1. 3D-FEA results of the ECPMS-machine for the models M1-M4

\begin{tabular}{l|c|c|c|c|c|c|c|c}
\hline \multicolumn{1}{c|}{ Model } & \multicolumn{2}{c|}{ M1 } & \multicolumn{2}{c|}{ M2 } & \multicolumn{2}{c|}{ M3 } & \multicolumn{2}{c}{ M4 } \\
\hline$I_{D C}(\mathrm{~A})$ & 0 & 2 & 0 & 2 & 0 & 2 & 0 & 2 \\
\hline$B_{I P}(\mathrm{~T})$ & -0.02 & 0.46 & -0.01 & 0.5 & -0.02 & 0.53 & -0.01 & 0.5 \\
\hline$B_{P M}(\mathrm{~T})$ & 0.49 & 0.59 & 0.3 & 0.38 & 0.36 & 0.49 & 0.31 & 0.43 \\
\hline$\Phi_{I P}(\mathrm{mWb})$ & -0.05 & 1.6 & -0.03 & 1.7 & -0.05 & 1.8 & -0.05 & 1.7 \\
\hline$\Phi_{P M}(\mathrm{mWb})$ & 1.6 & 2.0 & 0.98 & 1.2 & 1.2 & 1.7 & 1.1 & 1.5 \\
\hline
\end{tabular}

Moreover, the simulation results in Fig. 4 show an assessment of the effectiveness of field weakening and the values of determinants of the growth flux ratio $\Delta \Phi_{P M}, \Delta \Phi_{I P}$, as well as the control coil axial flux leakage $\Phi_{\text {leak } / I_{D C}}$, in comparison.

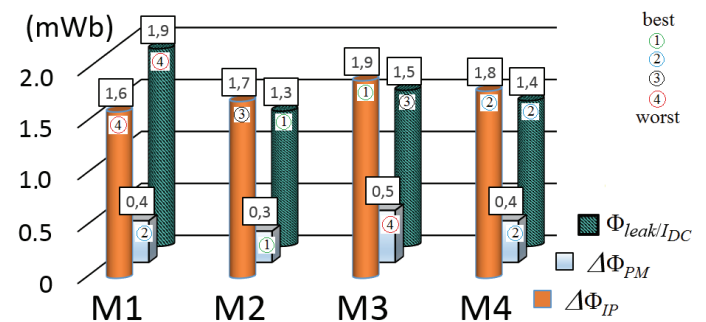

Fig. 4. Flux ratios: $\Delta \Phi_{P M}, \Delta \Phi_{I P}$, and the control coil axial flux leakage $\Phi_{\text {leak } / I_{D C}}$ for the M1-M4 models

Fig. 5 shows the 3D-FEA results of a no-load output voltage $E_{0}$ (Vrms) versus the control coil current for the load current $I_{D C}$ in the range of 0-2.0 A, which has been determined for the models M1-M4. These characteristics show that the excellent field-weakening capability of the machine is achieved in the rotor based on the M2 model. However, in this case, a low power density ratio occurs. Simulation results demonstrate that a good field-weakening feature is also obtained in the M4 model. Taking into account the technical feasibility of the rotor, it has been decided that the next work will focus on experimental validation of the ECPMSmachine with a rotor prototype based on the M4 model.

In this case, in order to perform an FEA, a three-dimensional meshed model of M4 (Fig. 6), containing approximately 395000 nodes, was developed, using the commercial Flux3D v.10.4.2 software package by Cedrat Ltd. 


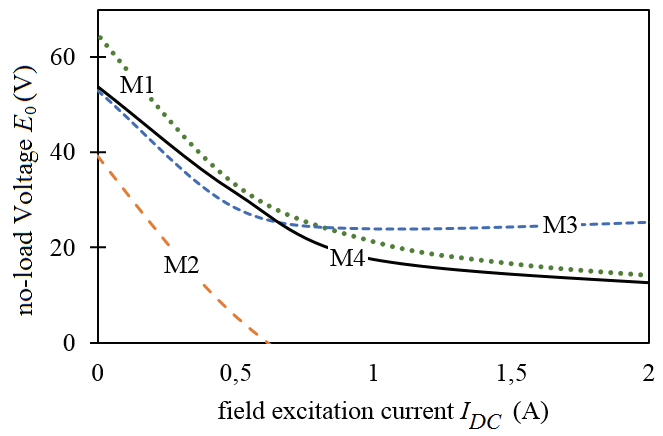

Fig. 5. No-load output terminal voltage $E_{0}$ versus the control coil current $I_{D C}$ characteristic

It should be noted that, due to the complexity of the machines' geometry, and its lack of symmetry, FEA computing time is long and costly. For instance, a single step to compute the half-period of the back-EMF waveform might take anywhere between 20 and 60 hours using a standard PC computer platform based on an Intel Core i7 processor. FEA computing time strongly depends on the saturation level of the machine and it is rapidly increased while the control coil current is increasing. For this reason, the research on the development of a simplified reluctance equivalent circuit of the machine for design purposes was independently conducted by the author in [14].
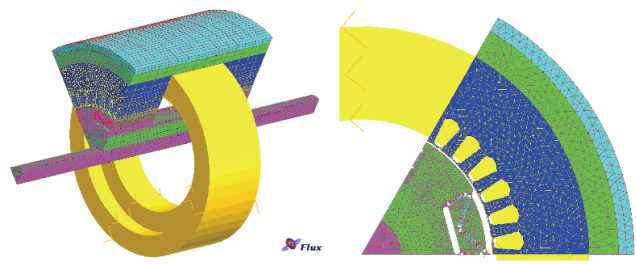

Fig. 6. Meshed 3-D model of M4

Furthermore, in order to showcase the complexity of the problem, Fig. 7 shows the 3-D distribution of the magnetic field in the active magnetic parts of the model without the control coil current $I_{D C}$ at no-load conditions (Fig. 7a), and at a nominal stator current $I_{s N}$ (Fig. 7b).

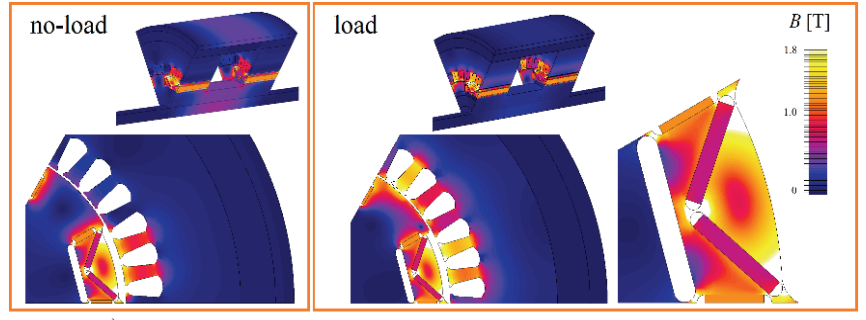

a)

b)

Fig. 7. Magnetic field distribution of the M4 model at $I_{D C}=0$; no-load $I_{S}=0$ (a) and nominal $I_{S}=I_{s N}(\mathrm{~b})$ stator current conditions 
Table 2 lists FEA predictions of a PM flux linked $\Psi_{P M}$ and inductances of the M4 model.

Table 2. Magnetic parameters of the M4 model

\begin{tabular}{c|r|c}
\hline & Value & Unit \\
\hline PM flux linkage, $\Psi_{m}$, & 122.6 & $\mathrm{mWb}$ \\
\hline$d$-axes inductance, $L_{d}$ & 4.4 & $\mathrm{mH}$ \\
\hline$q$-axes inductance $L_{q}$ & 5.5 & $\mathrm{mH}$ \\
\hline
\end{tabular}

The parameters are performed to analyze and predict the electromagnetic torque-position characteristic of the machine. The electromagnetic torque $T_{e}$ based on voltage and flux equations of the ECPMS-machine [6] is written as:

$$
T_{e}=\frac{3}{2} p\left[\Psi_{P M} i_{q}+M_{D C} i_{D C} i_{q}+\left(L_{d}-L_{q}\right) i_{d} i_{q}\right]
$$

where: $i_{q}, i_{d}$ are the $q$-axis and $d$-axis currents respectively, $M_{D C}$ is the DC control coil mutual inductance.

Fig. 8 presents the results of analytical and FEA predictions of static torque-position characteristics obtained at nominal current of stator winding condition $I_{s N}=30 \mathrm{~A} \mathrm{DC}$ for phase A and $15 \mathrm{~A}$ DC for phase B and C, and without the control coil current $I_{D C}=0$.

The characteristics reveal that a relatively small reluctance torque $\left(T_{\text {rel }}\right)$ is achieved, as the product of the difference of inductances $\left(L_{d}-L_{q}\right)$ and $i_{d}$ and $i_{q}$ currents, in comparison with a PM torque $\left(T_{P M}\right)$, as the product of the flux linkage $\Psi_{m}$ by the PMs and $i_{q}$ current. In this case, the PM torque remains the main torque of the machine. However, this causes that, in the low/high-operation range, the effectiveness of increasing/decreasing the air-gap flux linkage $\Psi_{m}$ will be closely linked to the DC field strengthening/weakening capabilities of the machine.

Moreover, Fig. 8 shows that the electromagnetic torque $T_{e \text { FEA }}$ obtained by FEA predictions and the electromagnetic torque $T_{e}$ insignificantly differ from each other due to a cogging torque characteristic (Fig. 9), which is neglected in the analytical model.

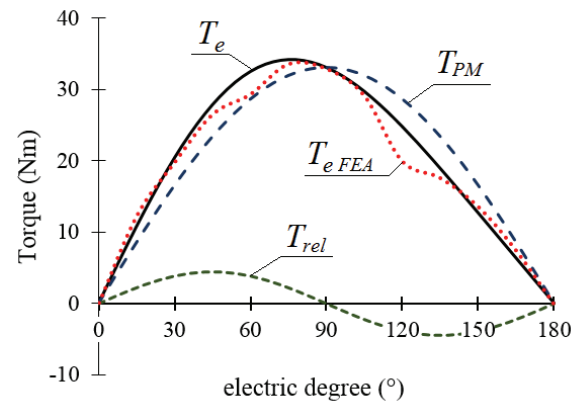

Fig. 8. Torque characteristics at nominal armature current $I_{s N}=30 \mathrm{~A}, I_{D C}=0$

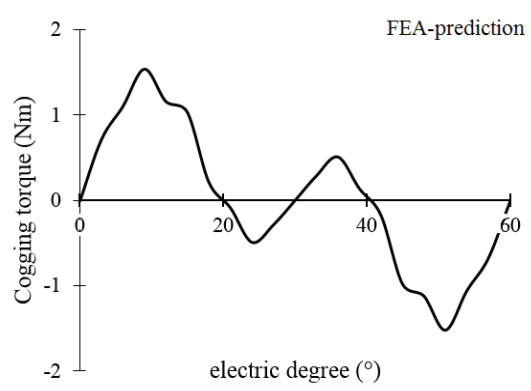

Fig. 9. Cogging torques vs. rotor position for 10 mech. deg. (60 el. deg.) at no-load condition $I_{s}=0, I_{D C}=0$ 
Fig. 10 shows FEA predictions of the torque-position characteristics at full-load conditions, while Fig. 11 shows the predicted performance (range of speed and torque) of the machine, estimated based on the FEA and analytical model results. In these studies, a maximum power supply voltage of $300 \mathrm{~V}$, a stator current $I_{s}$ up to $30 \mathrm{~A}$, and a maximal control coil current $I_{D C}$ up to $\pm 5 \mathrm{~A}$ were assumed.

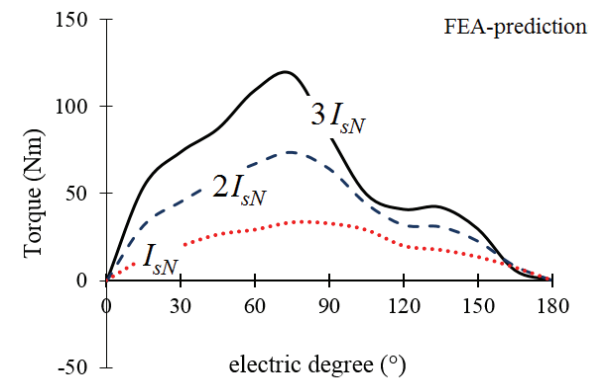

Fig. 10. Torques vs. rotor position at full-load armature current $1-3 \cdot I_{S N}$ without the control coil current $I_{D C}=0$

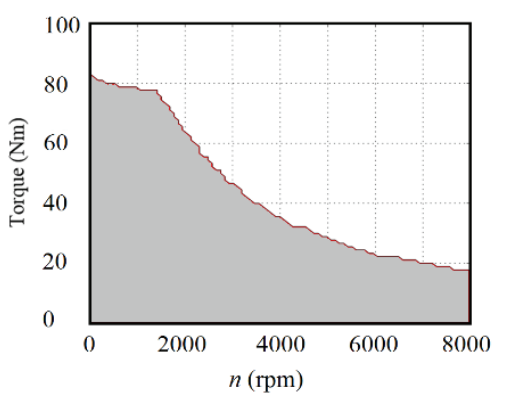

Fig. 11. The predicted operation region of the ECPMS-machine

\section{Experimental results}

Fig. 12(a) shows a sketch of a rotor magnetic structure based on the M4 model with a distinctive multiple flux barrier arrangement. Three types of flux barriers have been developed. The first one is a single flux barrier (SFB), located at the air-gap over the magnet pole section. The second type is an embedded flux barrier (EFB), located inside the rotor laminations. The third one is a radial flux barrier (RFB), which is radially formed and located inside the rotor magnetic structure.

The primary design data and guidelines for a machine prototype are presented in Table 3.

Table 3. Machine design requirements and assumption

\begin{tabular}{l|c|c}
\hline \multicolumn{1}{c|}{ Parameter } & Value & Unit \\
\hline Rotor outer diameter, $D_{r}$ & 163.0 & $\mathrm{~mm}$ \\
\hline Stator stack length, $l_{s}$ & $2 \times 80.0$ & $\mathrm{~mm}$ \\
\hline Air-gap length, $l_{g}$ & 0.5 & $\mathrm{~mm}$ \\
\hline Maximal speed, $n_{\max }$ & 8000 & $\mathrm{~min}^{-1}$ \\
\hline Maximal control coil current, $I_{D C}$ & \pm 5.0 & $\mathrm{~A}$ \\
\hline Voltage reduction ratio, $\Delta U_{0}$ & $1: 4$ at least & - \\
\hline Nominal stator current, $I_{s N}$ & 30.0 & $\mathrm{~A}(\mathrm{rms})$ \\
\hline Stator phase resistance, $R_{s}$ & 0.2 & $\Omega$ \\
\hline Pair-poles, $p$ & 6 & - \\
\hline
\end{tabular}


The assembled rotor prototype for the ECPMS-machine and its one part of laminations with the view of PMs are illustrated in Fig. 12(b). The lamination material used in the rotor prototype was a $0.5 \mathrm{~mm}$-thick steel sheet of M400-50A-C3. The PMs (N38SH) have a remanent flux density of $1.23 \mathrm{~T}$ and coercive force of $907 \mathrm{kA} / \mathrm{m}$. The PMs are inserted into two EFB and two RFB barriers. One open EFB barrier (without PM) is located closest to the axis of the machine.

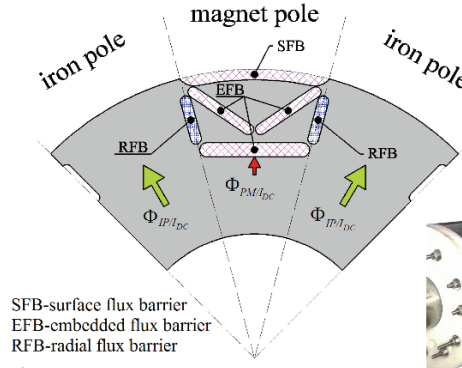

a)

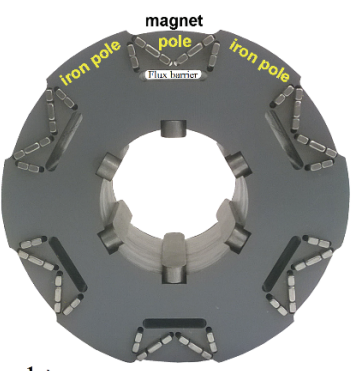

b)

Fig. 12. A sketch of the rotor magnetic structure (a) and the assembled rotor (b)

In order to ensure the effectiveness of the flux $\Phi_{I P}$ crossing the air-gap under the limitation of the iron pole section, experiments testing the back-EMF waveforms at different values of the control coil current $I_{D C}$ have been carried out. Fig. 13 shows the back-EMF waveforms obtained at a constant speed of $1000 \mathrm{rpm}$ and at $I_{D C}$ in the range from -5 to $6 \mathrm{~A}$. Moreover, based on these results, a no-load output terminal voltage $E_{0}\left(\mathrm{~V}_{\text {rms }}\right)$ versus $I_{D C}$ characteristic has been presented in Fig. 14.

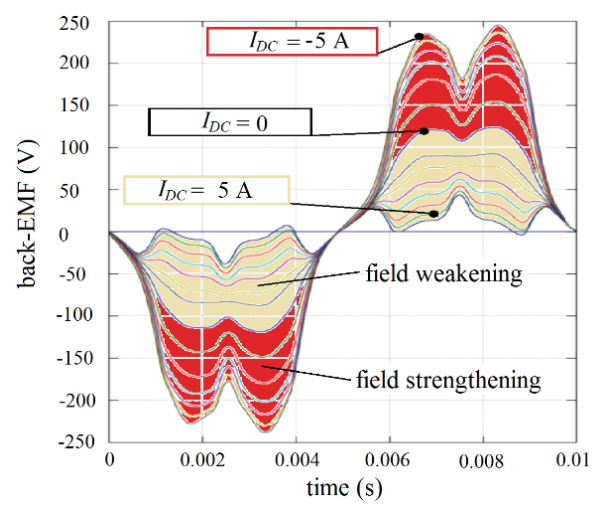

Fig. 13. Back-EMF waveforms under different control coil current $I_{D C}$ at $1000 \mathrm{rpm}$ constant speed

The presented results show an effective capability of magnetic field control for the ECPMS-machine based on the new rotor design. As presented, the voltage $E_{0}$ is effectively decreased from 53.0 to $12.0 \mathrm{~V}_{\text {rms }}$ for the loading control coil current range from 0 to $5.0 \mathrm{~A}$. Moreover, Fig. 14 shows a no-load output voltage reduction ratio $\Delta E_{0}$ that is determined by the ratio between the no-load output voltage without the additional excitation and the voltage 
induced at the field-weakening region. In this case, $\Delta E_{0}=4$ is successfully obtained at $I_{D C}=4.8 \mathrm{~A}$. This result is similar to the FEA predictions (for the M4 model) shown in Fig. 5.

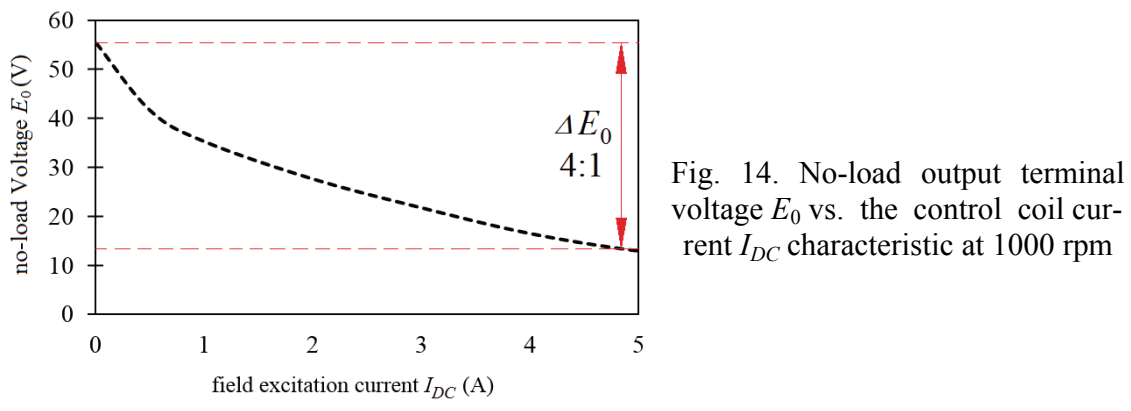

\section{Conclusions}

The purpose of the paper was to explore the magnetic structure of the modified ECPMSmachine and indicate novel rotor designs for the machine with high field weakening capability. Four different rotor designs have been discussed, including three new rotor concepts for the machine. Based on the 3-D FEA results, field-weakening features for all topologies have been presented. Moreover, the analysis has demonstrated that the proposed rotor machine configurations allow to control the flux in the air-gap without significantly affecting the magnetization characteristics of PMs. Particular attention has been paid to a rotor design concept based on the M4 model with flux barriers in the rotor magnetic structure. Furthermore, a prototype of the ECPMS-machine with a new rotor concept has been successfully tested. For this rotor design, the influence of magnets and flux barriers arrangement on controlling field excitation has been examined. The experiment results have shown that the field-weakening ratio equal to $4: 1$ is effectively obtained in the prototype of the machine, which implies its great application potential in the development of new BEV technology.

\section{Acknowledgements}

This work has been supported with the grant of the National Science Centre, Poland 2015/17/B/ST8/03251

\section{References}

[1] Amara Y., Hlioui S., Belfkira R. et al., Comparison of Open Circuit Flux Control Capability of a Series Double Excitation Machine and a Parallel Double Excitation Machine, IEEE, IEEE Transactions on Vehicular Technology, vol. 60, no. 9, pp. 4194-4207 (2011).

[2] Wang Y., Deng Z., Hybrid Excitation Topologies and Control Strategies of Stator Permanent Magnet Machines for DC Power System, IEEE Transactions on Industrial Electronics, vol. 59, no. 12, pp. 4601-4616 (2012). 
[3] Amara Y., Vido L., Gabsi M. et al., Hybrid excitation synchronous machines: energy-efficient solution for vehicles propulsion, IEEE Transactions on Vehicular Technology, vol. 58, no. 5, pp. 2137-2149 (2009).

[4] Paplicki P., Modified concept of axial-flux permanent magnet machine with field weakening capability, Archives of Electrical Engineering, vol. 63, no. 2, pp. 177-185 (2014).

[5] Mingming H., Xinjun G., Ping J. et al., Flux-weakening control methods for hybrid excitation synchronous motor, Archives of Electrical Engineering, vol. 64, no. 3, pp. 427-439 (2015).

[6] Paplicki P., Wardach M., Bonislawski M., Palka R., Simulation and experimental results of hybrid electric machine with a novel flux control strategy, Archives of Electrical Engineering, vol. 64, no. 1, pp. 37-51 (2015)

[7] Putek P., Paplicki P., Palka R., Topology Optimization of rotor poles in a Permanent-Magnet machine using Level Set method and Continuum Design Sensitivity Analysis, COMPEL, vol. 33, no. 3, pp. 711-728 (2014).

[8] Putek P., Paplicki P., Palka R., Low cogging torque design of Permanent-Magnet machine using modified multi-level set method with total variation regularization, IEEE Transactions on Magnetics. vol. 50, no. 2, article no. 7016204 (2014).

[9] Paplicki P., Optimization of Electrically Controlled Permanent Magnet Synchronous Machine to Improve Flux Control Range, Elektronika ir Elektrotechnika, vol. 20, no. 10, pp. 17-22 (2014).

[10] Di Barba P., Bonislawski M., Palka R. et al., Design of Hybrid Excited Synchronous Machine for Electrical Vehicles, IEEE Transactions on Magnetics, vol. 51, no. 8, article no. 8107206 (2015).

[11] Paplicki P., Effect of rotor structure on flux weakening characteristics of ECPM synchronous machine, Zeszyty Problemowe - Maszyny Elektryczne, vol. 107, no. 3, pp. 183-187 (2015).

[12] Paplicki P., ECPMSM synchronous machine - selected simulations and designing results, Zeszyty Problemowe - Maszyny Elektryczne, vol. 103, no. 3, pp. 109-114 (2014).

[13] Gieras J., PM synchronous generators with hybrid excitation systems and voltage control Capabilities, A review, XX International Conference on Electrical Machines (ICEM), Marseille, pp. 2573-2579 (2012).

[14] Paplicki P., Simplified Reluctance Equivalent Circuit for Hybrid Excited ECPMS-Machine Modelling, Proceedings of the $21^{\text {th }}$ International Conference on Methods and Models in Automation an and Robotics (MMAR), pp. 241-244 (2016). 